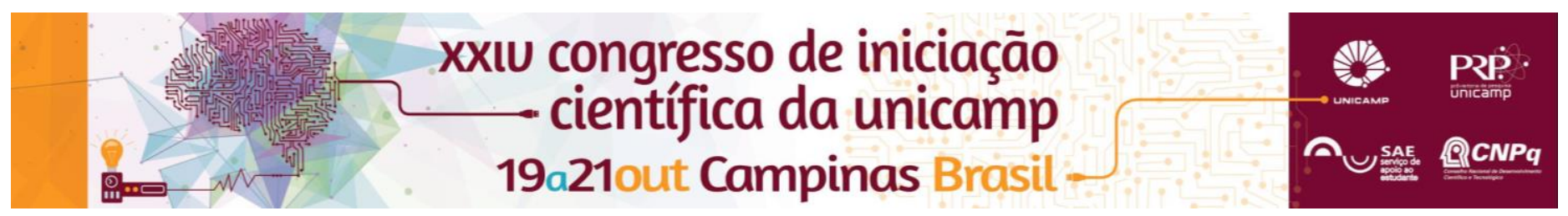

\title{
Desempenho do besouro especialista Chelymorpha cribraria (Chrysomelidae: Cassidinae) em duas plantas hospedeiras do gênero Ipomoea (Convolvulaceae)
}

\section{Douglas Menezes de Souza*, José Roberto Trigo}

\begin{abstract}
Resumo
A especificidade em interações inseto-planta hospedeira restringem a alimentação enquanto larva a um gênero ou família da planta hospedeira. Dentro de um mesmo gênero existem espécies de plantas hospedeiras que conferem uma melhor aptidão para os insetos especialistas, pois devem compartilhar a sua história evolutiva com os insetos. Nesse trabalho investigamos o desempenho do Chelymorpha cribraria (Chrysomelidae: Cassidinae) em duas plantas hospedeiras do gênero Ipomoea (Convolvulaceae) e propomos um cenário evolutivo, envolvendo adaptação local, para o desempenho diferencial nessas espécies de plantas hospedeiras.
\end{abstract}

\section{Palavras-chave}

adaptação local, herbivoria, interação planta-inseto

\section{Introdução}

A especificidade em interações inseto-planta hospedeira restringem a alimentação enquanto larva a um gênero ou família da planta hospedeira. Dentro de um mesmo gênero existem espécies de plantas hospedeiras que conferem uma melhor aptidão para os insetos especialistas, pois devem compartilhar a sua história evolutiva com os insetos. Esse padrão deve ter como origem a adaptação local, onde organismos de uma população evoluíram diferencialmente quando comparados com outras populações da mesma espécie em resposta a algum fator abiótico ou biótico do seu ambiente local (Kawecki 2004). Nesse trabalho investigamos o desempenho do besouro especialista Chelymorpha cribraria (Chrysomelidae: Cassidinae) em duas plantas hospedeiras do gênero Ipomoea (Convolvulaceae): I. cairica e I. carnea fistulosa. Como I. cairica apresenta uma distribuição ampla nos Neotrópicos e I. carnea fistulosa tem o seu centro de origem restrito a região do Pantanal Mato-grossense, nós levantamos a hipótese que populações de $C$. cribraria da região Sudeste do Brasil apresentariam um melhor desempenho em $I$. cairica do que em I. carnea fistulosa, por compartilharem sua história evolutiva com a primeira espécie, mas não com a segunda. Em outras palavras, sugerimos que as populações de $C$. cribraria sejam adaptadas localmente às suas plantas hospedeiras

\section{Resultados e Discussão}

Medimos a sobrevivência de larvas de $1^{\circ}$ instar até pupa, o tempo de desenvolvimento larval até pupa e a massa da pupa em larvas criadas em folhas de $I$. cairica ou folhas de I. carnea fistulosa. Em I. cairica, a sobrevivência de $C$. cribraria foi significativamente maior, o tempo de desenvolvimento significativamente menor e a massa de pupa significativamente maior, quando comparada com C. cribraria em I. carnea fistulosa (Figura 1).

Esses resultados suportam a nossa hipótese que populações de C. cribraria da região Sudeste do Brasil apresentariam um melhor desempenho em I. cairica do que em I. carnea fistulosa, por compartilharem sua história evolutiva com a primeira espécie, mas não com a segunda.
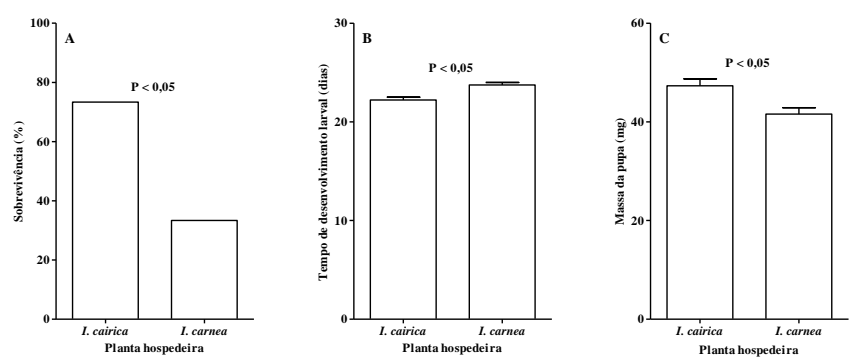

Figura 1. Desempenho do besouro Chelymorpha cribraria em folhas de Ipomoea cairica e lpomoea carnea fistulosa. (A) Sobrevivência, (B) tempo de desenvolvimento larval e (C) massa da pupa.

\section{Conclusões}

Os nossos resultados sugerem que populações do Sudeste brasileiro são adaptadas localmente às plantas hospedeiras nativas. Estudos com populações de outras regiões, além de experimentos de transplante recíproco, são necessários para que a hipótese de adaptação local seja suportada.

\section{Agradecimentos}

Agradecemos a FAPESP (2011/17708-0) e CNPq (306103/2013-3) pelo apoio financeiro.

Kawecki T (2004) Conceptual issues in local adaptation. Ecology Letters 1225 1241. 